Etnográfica

Revista do Centro em Rede de Investigação em

Antropologia

vol. $18(2) \mid 2014$

Vol. $18(2)$

\title{
A década de 1990: os anos da internacionalização
}

The nineties, or, the years of internationalization

\section{Cristiana Bastos}

\section{(2) OpenEdition \\ Journals}

\section{Edição electrónica}

URL: https://journals.openedition.org/etnografica/3752

DOI: 10.4000/etnografica.3752

ISSN: 2182-2891

\section{Editora}

Centro em Rede de Investigação em Antropologia

\section{Edição impressa}

Data de publição: 1 junho 2014

Paginação: 385-401

ISSN: 0873-6561

Refêrencia eletrónica

Cristiana Bastos, «A década de 1990: os anos da internacionalização», Etnográfica [Online], vol. 18 (2)। 2014, posto online no dia 09 julho 2014, consultado o 10 fevereiro 2022. URL: http://

journals.openedition.org/etnografica/3752 ; DOI: https://doi.org/10.4000/etnografica.3752

\section{(c) (i) (9)}

Etnográfica is licensed under a Creative Commons Attribution-NonCommercial 4.0 International License. 


\section{A década de 1990: \\ os anos da internacionalização}

\section{Cristiana Bastos}

Este artigo responde à solicitação de descrever, a partir da experiência pessoal, as transformações na antropologia portuguesa nos anos 1990, também chamados "os anos da internacionalização". Combinando a análise das dinâmicas de internacionalização que transformaram para sempre a antropologia portuguesa e a narrativa na primeira pessoa de uma experiência de internacionalização que passou pelos Estados Unidos e pelo Brasil, exploro algumas tendências, protagonistas, factos e pequenas histórias que marcaram essa década e influenciaram as que se seguiram.

PALAVRAS-CHAVE: EASA, Congresso Luso-Afro-Brasileiro de Ciências Sociais, antropologia americana, antropologia brasileira, globalização, antropologia médica.

The nineties, or, the years of internationalization - This article describes the transformations in Portuguese anthropology during the 1990s, both as experienced by the author in connections to North American and Brazilian anthropology and as experienced by the community of Portuguese social scientists, which hosted in 1990 two international conferences that were key to the dynamics of internationalization in that decade: the first EASA meeting and the first Luso-Afro-Brazilian Social Sciences Conference.

KEYWORDS: EASA, Luso-Afro-Brazilian Social Sciences Conference, American anthropology, Brazilian anthropology, globalization, medical anthropology.

BASTOS, Cristiana (c.bastos@ics.ul.pt) - Instituto de Ciências Sociais, Universidade de Lisboa, Portugal.

[Nota] Por opção da autora, o artigo é publicado usando a ortografia anterior à estabelecida pelo Acordo Ortográfico de 1990. 


\section{O ANO DE 1990: DOIS CONGRESSOS INTERNACIONAIS EM PORTUGAL}

Em 1990 ocorreram duas reuniões científicas que vieram a influenciar irreversivelmente os caminhos da antropologia no nosso país. Eram encontros exploratórios, primeiras edições, tentativas de criar algo novo que poderia ter ficado por ali; mas foram o começo de um período de mudança na circulação, interlocuções e modos de praticar a antropologia em Portugal - o que depois chamámos internacionalização.

Os dois congressos assinalavam duas linhas que até hoje se mantêm em coexistência pacífica, com algumas zonas de sobreposição, porém áreas de influência distintas: por um lado, o eixo lusófono, transcontinental, que reconfigura criticamente e em lógica pós-colonial os nexos forjados no império, propondo o uso da língua portuguesa como instrumento de trabalho científico; por outro, o eixo europeu, de línguas, tradições e nacionalidades múltiplas, tolerante para com as variedades regionais da antropologia e do pensamento, sem deixar de cultivar a hegemonia anglófona que hoje se generalizou para quase todos os campos científicos.

Examinemos de perto as dinâmicas que levaram a cada um desses encontros científicos. No eixo dito lusófono, eram mínimos os contactos entre as várias comunidades académicas de língua portuguesa e generalizado o desconhecimento mútuo. Os poucos portugueses que frequentavam universidades internacionais geralmente iam para o centro e norte da Europa ou, em menor quantidade, para os Estados Unidos. Raros eram os que tinham conhecimento directo dos ambientes universitários brasileiros, e o conhecimento das universidades africanas resumia-se largamente aos contactos estabelecidos em situações de cooperação e assistência internacional ou, para os mais antigos, no próprio regime colonial. Com vista a criar pontes entre os grupos separados pelo espaço e instituições, o Centro de Estudos Sociais (CES) da Universidade de Coimbra promoveu o primeiro Congresso Luso-Afro-Brasileiro de Ciências Sociais. Teve como principal impulsionador Boaventura de Sousa Santos, sociólogo de trajecto original que incluía os Estados Unidos (Yale, e mais tarde Madison-Wisconsin) e o Brasil (Rio de Janeiro).

Foi apenas o início de uma convergência necessária e muito saudada, gerando-se uma dinâmica que não mais parou, entusiasmando universidades, pesquisadores, estudantes e patrocínios. A comunidade foi crescendo e intensificando os laços em encontros que ocorreram a cada dois anos, sucessivamente em São Paulo (1992), Lisboa (1994), Rio de Janeiro (1996), Maputo (1998), Porto (2000), novamente Rio (2002), novamente Coimbra (2004), Luanda (2006), Braga (2008), Baía (201 1), prevendo-se o seguinte para Cabo Verde. ${ }^{1}$ Criou-se uma revista, uma associação, acções conjuntas, pesquisas

1 Durante a revisão final deste texto esta situação modificou-se e o $12 .^{\circ}$ Congresso terá lugar em Lisboa, em Fevereiro de 2015. 
articuladas, mas sobretudo desenvolveu-se uma plataforma de onde partiram muitas outras, em continuidade ou em contraste, que teceram as malhas de uma comunidade transnacional em que o português é usado como língua de trabalho e os estudantes e pesquisadores circulam entre países e instituições, ampliando os seus universos de pesquisa, conceptualização e interlocução.

Em paralelo, também em 1990 e também na cidade de Coimbra, onde nascia um novo e dinâmico departamento de antropologia, deu-se a primeira reunião da European Association of Social Anthropologists (EASA). O seu principal dinamizador foi João de Pina-Cabral, antropólogo de carreira internacional formado na Witwatersrand (África do Sul) e em Oxford (UK) e radicado em Portugal, quadro do Instituto de Ciências Sociais da Universidade de Lisboa; foi coadjuvado por José António Fernandes Dias, antropólogo da Escola de Belas-Artes de Lisboa, e pelos demais colegas de Coimbra que, em conjunto, criaram condições de excelência para uma reunião que definitivamente pôs Portugal no mapa da antropologia europeia.

O I Encontro da EASA foi um sucesso, e produziu novas edições a cada dois anos; circulou pelos espaços europeus - Praga (1992), Oslo (1994), Barcelona (1996), Frankfurt (1998), Cracóvia (2000), Copenhaga (2002), Viena (2004), Bristol (2006), Liubliana (2008), Maynooth (2010), Paris (2012) - atravessando línguas, criando redes e comunidades em torno de interesses comuns, urgências sociais e outras emergências na interpretação e análise. Portugal e os antropólogos portugueses passaram a integrar em pleno este universo. A situação periférica que marcara o passado dava agora lugar a uma paridade que, nesses prósperos anos 90, se celebrava com quase eufórico entusiasmo: os portugueses deixavam de "ir à Europa" e passavam a "estar na Europa", a pensar-se e praticar-se europeus. Note-se que a década de 90 intensificou a circulação para quase todos, pondo fim às barreiras que dividiam e separavam mundos paralelos, aos muros - como o de Berlim, que existia em toda a materialidade - e outros impedimentos à troca de ideias e ao pensamento crítico sobre o qual assentam as ciências sociais e a antropologia. Havia também muros menos visíveis, intangíveis, separando e dividindo por língua, por tradição académica, por local, por diferenças de riqueza e status, por diferenças de cidadania no acesso ao conhecimento. Assim era antes de 1990. ${ }^{2}$

2 Dois outros encontros marcaram para alguns antropólogos portugueses o início da internacionalização: o Congresso de Sociologia Rural em Braga (1985), que acolheu um grande número de antropólogos que trabalhavam sobre Portugal e Espanha, nesse tempo em que dominavam os estudos de situações rurais; e o encontro de antropologia do Estado espanhol, em Alicante (IV Congresso de Antropologia de Espanha, 1987), em que estiveram presentes vários estudantes e professores portugueses que ali estabeleceram laços que duraram pelas décadas seguintes. 


\section{ANTES DE 90 EM PORTUGAL}

Durante o regime político que se manteve em Portugal até 1974 o lugar da antropologia era limitado. Havia um nicho de produção etnográfica que dava apoio à administração colonial, preparando os quadros no conhecimento de sociedades africanas e asiáticas, promovendo ou musealizando costumes locais, desenvolvendo missões às colónias para recolhas etnológicas e antropométricas, ou relatórios secretos para o governo em que se avaliava o estado de pacificação ou rebelião dos povos; havia também o vasto trabalho de levantamento etnográfico, recolha e sistematização empreendido pelo Centro de Estudos de Etnologia Peninsular (CEEP), que passara por entre as malhas da vigilância política. Abundantes as narrativas etnográficas e escassos os desenvolvimentos teóricos e a análise crítica, ausentes as condições de liberdade ou de estruturas materiais que poderiam permiti-lo, era como se a antropologia estivesse incompleta.

Entretanto, fora do país, em trajectórias internacionais singulares feitas de iniciativa própria, por vezes em rotas de exílio para ambientes livres, alguns portugueses formaram-se em antropologia; alguns regressaram depois de 1974. E chegaram também alguns mais, exilados de outras ditaduras noutros lugares, ou em rota de investigação com terreno em Portugal. Deste modo, já nos anos 80 havia entre nós um largo número de antropólogos que tinham passado por universidades francesas, inglesas, alemãs, belgas (Joaquim Pais de Brito, Robert Rowland, João de Pina-Cabral, José Carlos Gomes da Silva, Raúl Iturra, Pedro Prista, Jorge Freitas Branco, Brian O’Neill). Dos outros, muitos se tinham já formado nos eixos do Instituto Superior de Ciências Sociais e Políticas (ISCSP) pós-1974 (João Leal, Rosa Maria Perez) ou recebido formações múltiplas (José Gabriel Pereira Bastos), até que surgiu uma licenciatura específica na FCSH-UNL que formou uma geração de novos antropólogos nacionais (Manuela Palmeirim e Rui Pereira na primeira edição, depois o ano que frequentei, com Maria Cardeira da Silva, Graça Cordeiro, Ana Isabel Afonso, entre outros, e logo a seguir Miguel Vale de Almeida, Clara Saraiva, Clara Carvalho, Francisco Vaz da Silva e muitos mais); e preparava-se uma outra geração no ainda mais recente departamento de antropologia no Instituto Superior de Ciências do Trabalho e da Empresa (ISCTE, de onde saíram António Medeiros, Paulo Raposo, Filipe Reis, Nuno Porto, Antónia Pedroso de Lima, Susana Viegas, Francisco Oneto Nunes e muitos outros). A antropologia vibrava. Mas vibrava sobretudo dentro de portas; circulava-se pouco no exterior, não havia capacidade de intervir em debates internacionais. No interior do país sim, circulava-se, havia que reduzir o défice de conhecimento instalado, produzir etnografias que substituíssem as mitografias do regime anterior. Um livro simboliza esse movimento melhor que qualquer outro: Lugares de Aqui: Actas do Seminário Terrenos Portugueses, 
editado por Joaquim Pais de Brito e Brian O’Neill na Dom Quixote em 1991, com capítulos de João Leal (Açores), Jorge Freitas Branco (Madeira), João de Pina-Cabral (Minho), Pedro Prista (barrocal algarvio), Cristiana Bastos (serra algarvia), Joaquim Pais de Brito (Trás-os-Montes), Brian O’Neill (Trás-os-Montes), Raúl Iturra (Beira Alta), Graça Cordeiro (Lisboa) e Miguel Vale de Almeida (a ideologia nos livros de instrução primária pré-1974).

\section{NOTA PESSOAL, PRÉ-1990}

Fiz-me antropóloga nesse contexto. Formei-me na Faculdade de Ciências Sociais e Humanas da Universidade Nova de Lisboa (FCSH-UNL), onde ainda ouvi e li muita antropologia estrutural, bilinas de ossetas que nunca viria a conhecer, ciclos de mitos amazónicos que viria apenas a tangenciar, etnografias longínquas e tão exóticas quanto eram, por vezes, de outras eras de pensamento; onde fiz amizades que perduraram; onde a escassez de livros era tal que para lermos tínhamos de atravessar a cidade de autocarro até ao Restelo, para ter acesso aos livros e revistas de antropologia da sempre acolhedora biblioteca do Museu de Etnologia.

Para completar a licenciatura fazíamos um minitrabalho de campo, lançados ao mundo real sem bóias nem protectores, quase sem ideia de como se fazia pesquisa, com pouco instrumental teórico, mas capazes de percorrer um exercício de iniciação que continha a equação de base do terreno, isto é, saber entrar, permanecer, sair. Fazíamo-lo planeando, escolhendo, partindo, entrando, interagindo, comunicando, depois interpretando, escrevendo, fechando a análise numa peça apresentável - tudo num tempo concentrado, quase instantâneo, uma amostra do que viria a ser depois uma tese verdadeira, um vislumbre do que viria a ser a experiência de terreno e respectiva escrita.

Acerca das vantagens e desvantagens deste tipo de iniciação ao terreno dividiam-se os colegas da FCSH, que frequentei, e os do recém-criado departamento de antropologia do ISCTE, cujo quadro integraria pouco tempo depois (mas não o sabia ainda). Fiz o prematuro "terreno" com estadias intermitentes na fronteira do Alentejo, em Barrancos, escrevi a monografia pedida, que nunca mais li nem publiquei, a não ser, quase vinte anos mais tarde, em artigo numa revista americana de estudos portugueses (Bastos 1998a).

E logo a seguir, numa atitude que a vida confirma ser um padrão pessoal, mudei imediata e radicalmente de tema; dois dias depois de "defender a tese" (de licenciatura) estava a caminho da serra algarvia oriental para prospecção de um novo campo. Tinha entretanto conhecido a equipa do Campo Arqueológico de Mértola e do seu dinamizador Cláudio Torres, detentor de um pensamento original, instigador de gerações inteiras e de todo um modo de pensar as questões do Mediterrâneo e as continuidades materiais, culturais, sociais nos seus espaços. Fizemos logo em Dezembro de 1982 uma pequena expedição 
na qual iam também a Clara Saraiva, que procurava um terreno para a sua monografia de licenciatura, e o Luís Pavão, a fotografar um mundo em vias de transformação radical; nos anos seguintes faríamos juntos um levantamento etnográfico e museológico inspirado pelos trabalhos do CEEP.

Ali regressei ao longo da década de 80 e ali encontrei não apenas uma comunidade que me acolheu para o convencional trabalho de campo, mas também um conjunto notável de róis de confessados, que eram o documento mais desejado no âmbito da antropologia histórica, que ganhava expressão em Portugal e como era praticada por antropólogos que entretanto fui conhecendo fora da FCSH - Brian O’Neill, Robert Rowland, alguns outros que frequentavam o núcleo de demografia histórica da Gulbenkian que então funcionava em Oeiras. Trabalhar cruzando o presente e o passado, dando espessura temporal ao conhecimento etnográfico colhido ao vivo, permitiu-me propor uma interpretação alternativa ao fatalismo de abandono endossado e repetido à exaustão pelas agências de desenvolvimento e organismos estatais que geriam ou falavam pelo nordeste algarvio; em vez de declínio contínuo de uma idade do ouro para o presente, prevendo a sua substituição por florestas (de eucaliptos, como se via por todo o país, para proveito rápido?), detectei ciclos migratórios de longo prazo. Para essa análise tive o apoio de um outro grande mestre, o historiador Vitorino Magalhães Godinho; e tive também a companhia dos então meus colegas do ISCTE (onde entretanto tinha ingressado como docente), Jorge Freitas Branco e Pedro Prista, na equipa do Raúl Iturra; na fase final contei ainda com os comentários do João de Pina-Cabral, entretanto regressado de um período longo em Inglaterra - e manteríamos a interlocução por muito mais tempo, tendo eu mesma ingressado no ICS uns anos depois. Sobre o assunto fiz a tese de mestrado, que gerou o livro Os Montes do Nordeste Algarvio e vários artigos (Bastos 1985, 1988, 1991a, 1991b, 1993, 1996a, 1997a).

\section{INTERNACIONALIZAÇÃO PESSOAL I: NEW YORK, NY}

Repetindo uma tendência já enunciada, no dia imediatamente a seguir a entregar a tese de mestrado parti para os Estados Unidos. Pensava então que nos Estados Unidos, liberta da difícil escolha entre a etnologia francesa que ainda influenciara a minha formação e a antropologia social britânica que traziam os colegas anglófonos, ia poder explorar enfim à vontade a riqueza desse mundo que tinha começado a analisar na serra algarvia, contando ao mesmo tempo com a possibilidade de ter boa supervisão teórica e acesso a bibliotecas, livros, revistas. Em Portugal, com sorte, tínhamos fotocópias tiradas de livros emprestados pelos professores; nos Estados Unidos tínhamos os livros, em várias edições... e os seus autores, em directo, nas aulas, nos seminários, nas recepções, nos gabinetes. Era todo um outro universo de possibilidades, de promessa de 
condições para estudar mais e melhor e para trabalhar, além de mais e melhor, em liberdade. ${ }^{3}$

Pouco depois de chegar aos Estados Unidos percebi que tudo ia ser diferente do que tinha planeado. Esperava-se que começasse um tema novo, e assim aproveitei para explorar um interesse de longa data, no qual tocara superficialmente e sem supervisão: a antropologia médica ou da saúde. Inscrevi-me em todas as cadeiras de antropologia médica e afins que encontrei, tanto na City University of New York (CUNY) como na New School for Social Research; fiz os cursos de Shirley Lindenbaum, Leith Mullings, Ida Susser, David Rosner, e muitos mais; li e explorei em diversas direcções, até que, fazendo curta uma história longa, me dediquei àquilo que era o grande tema de Nova Iorque, a epidemia de sida.

Nos seminários de antropologia médica os trabalhos sobre sida eram maioritários; estávamos nos finais dos anos 80, e Nova Iorque era ao mesmo tempo um lugar de holocausto e de uma incomparável criatividade, de iniciativas políticas, trabalhos comunitários, intervenções artísticas, investigação clínica, de laboratório e de estudos sociais. A antropologia em Nova Iorque é conhecida por estudar temas contemporâneos e relevantes, e este era um deles. E eu, que vinha de uma antropologia ainda balbuciante, onde era exibido o pudor de tratar temas de impacto imediato, com medo de se confundir a disciplina com a acção e serviço social, onde se repetia o mantra do distanciamento entre as ciências sociais e os problemas sociais, entrava agora numa antropologia que dispensava esse distanciamento e, pelo contrário, advogava a pesquisa nos problemas da realidade imediata, deles fazendo a carne e o sangue da teoria. Estudava-se os sem-abrigo que enchiam as ruas de Nova Iorque na sequência do desmantelamento de programas sociais pela administração Reagan; o desmatamento na Amazónia; a proletarização de camponeses nos Andes e em África; a violência doméstica; a máfia; as sexualidades não hegemónicas; as identidades em mutação; cognições e práticas em saúde, doença, aflição, mas também a política global, o sistema-mundo, as redes transnacionais, o capitalismo, a moda, a vida social das coisas, além dos cânones da disciplina, a sua história, os estudos de área. Se estudar a epidemia de sida na perspectiva da antropologia era então impensável em Portugal, era absolutamente natural

3 Nesse tempo pré-FCT não era tarefa fácil conseguir financiar um doutoramento fora do país - algo que consegui graças à combinação de diversas fontes ao longo de diferentes períodos. Aproveito o momento para exprimir a minha gratidão: ao ISCTE, que me concedeu equiparação a bolseira, e mais tarde ao ICS, que me permitiu continuar o doutoramento; à comissão Fulbright, que me abriu diversas portas nos Estados Unidos e providenciou apoio, ao qual se acrescentou uma bolsa de mérito da fundação Delta Kappa Gamma; ao Graduate Center da City University of New York (CUNY), que me acolheu e apoiou; à JNICT-Invotan, que me apoiou numa fase seguinte; e à Wenner-Gren Foundation for Anthropological Research, que apoiou o trabalho de campo. 
fazê-lo a partir de Nova Iorque. Menos convencional era, mesmo aí e então, a perspectiva que utilizei - o ângulo da produção do conhecimento científico.

Estávamos muito antes da popularização dos estudos de laboratório, das teorias de actor-rede, da consagração de Latour e Callon na antropologia. Embora houvesse um consenso sobre a natureza social e cultural do conhecimento, embora houvesse etnociências e antropologia cognitiva, pouco se tinha feito na antropologia de finais dos anos 80 no que tocava ao exame directo da ciência produzida nos laboratórios enquanto fenómeno social. Mas, lá está, nessa maravilhosa biblioteca e nesse tempo em que as podíamos explorar à vontade, dei com um review article que me transformou para sempre: chamava-se "Opening Pandora's box" e, a propósito do livro do mesmo nome de Nigel Gilbert e Michael Mulkay (1984), revia os argumentos de Latour e Woolgar, Karin Knorr-Cetina, Michael Mulkay, Nigel Gilbert, Harry Collins, e outros tantos ilustres desconhecidos para a maioria dos departamentos de antropologia. A partir daí entrei no mundo nascente dos "STS" (para Science and Technology Studies, ou Estudos de Ciência e Tecnologia) que hoje têm espaço próprio na American Anthropological Association (AAA); essa passagem descrevi-a num capítulo de um livro sobre os Estudos Sociais da Ciência em Portugal (Bastos 2008a).

Fiquei assim voluntariamente presa aos estudos de ciência - mas também a outras coisas. Nesses três anos de cursos, tutoriais e supervisão expus-me a abordagens e desenvolvimentos teóricos que eram praticamente desconhecidos em Portugal. O livro Writing Culture já fora publicado e criticado; vi-o chegar a Portugal anos mais tarde, e criar inquietações por vezes paralisantes entre colegas e alunos, quando, no lugar de origem, viera e partira, deixando marcas mas não cicatrizes. O momento pós-moderno foi efémero e em Nova Iorque sentia-se o seu desigual impacto: nalgumas aulas o reflexivismo imperava e até capturava alguns reféns da impossibilidade de prosseguir no real (ou seria na obsessão com a própria voz, imagem, umbigo?); noutras fazia-se etnografia à antiga, por desconstruir, sólida no seu positivismo e nas suas convicções sobre a possibilidade de conhecer e medir o mundo; noutras ainda exploravam-se caminhos novos, digerido o reflexivismo, reduzido a uma peça de autocrítica que pouco muda no nosso desejo e esforço de interpretar a realidade social. Segui as aulas de Vincent Crapanzano, Eric Wolf, Jane Schneider, além dos que referi na antropologia e história da saúde; fiz area studies sobre lugares que nunca visitei mas fiquei a conhecer; e segui com devoção os cursos dos visitantes Fredrik Barth e Ulf Hannerz. Com este aderi à proposta de "global framework", à ambição de estudar fenómenos globais, à macro-antropologia. Ainda o "transnacionalismo" não se tinha instalado no vocabulário antropológico nem se enquistara o hábito de creditar o "trabalho multissituado" a George Marcus.

Era, sem dúvida, um momento excitante para a antropologia, não obstante pairasse no horizonte, também nos Estados Unidos, uma certa angústia quanto à possibilidade de prosseguir carreiras académicas e científicas; o que fora um 
lugar de plenitude na geração anterior era agora visto como um lugar de escassez, e quem quisesse emprego teria de circular por lugares remotos, pequenos colleges em estados do interior, ou tarimbar em tarefas precárias e mal pagas nas cidades, antes de arranjar uma posição mais à medida dos seus desejos e aspirações. Estes horizontes não se me puseram, já que mantinha o compromisso de regressar mais tarde a Portugal, fora equiparada a bolseira, escolhera usar no início o tempo de dispensa que habitualmente era dado para a fase final de redacção da tese.

Os horizontes que se me punham eram os de rasgar ideias novas e usar os ingredientes analíticos de que agora dispunha para tratar algo novo. Ideias não faltavam. E o modelo teórico desenhava-se na confluência dos meus interesses, dos vários que entretanto tinham emergido: os estudos sociais de ciência, a macro-antropologia, a epidemia de sida. A minha tese seria a combinação dessas três vertentes e, por isso, ainda hoje é difícil situá-la entre as subespecialidades. Até no título se instalou a transição conceptual - se a tese propriamente dita se chamaria Transnational Responses to AIDS and the Gobal Production of Science: A Case-Study from Rio de Janeiro (Bastos 1996c), o livro, publicado logo a seguir pela Indiana University Press, seria Global Responses to AIDS: Science in Emergency (Bastos 1999). Da primeira versão para a segunda perdeu-se a habitual referência ao lugar específico ou ao grupo étnico em que o trabalho de campo decorreu, típico da etnografia clássica e muitas vezes associado à crença na autoridade narrativa e analítica dos antropólogos, quando não na apropriação de um povo ou lugar em consequência do trabalho de campo. Estávamos numa transição, no decorrer da qual alguns se deram mesmo ao extremo de dispensar o terreno e a etnografia - que o tempo veio a repor, mantendo o terreno a sua centralidade na disciplina, mesmo quando em campos insólitos, ou, como vim depois a fazer, em arquivos do passado.

Encontrava-me nestes preparos teóricos quando tive a sorte de receber um estímulo à investigação sob a forma de bolsa de viagem para prospecção de terreno. Era o ano de 1989 e ainda não tinha escolhido o lugar de terreno; pendia sobre mim o regresso a Portugal a qualquer momento, o relógio da licença ouvia-se alto, sabia que não podia arriscar algo que envolvesse muito tempo por exemplo anos de aprendizagem de língua -, mas estava aberta a muitas latitudes, desde o Mediterrâneo, que prolongava o que tinha começado, à África, que tinha aprendido mas não conhecido. Por um conjunto de circunstâncias fui fazer uma prolongada exploração à América do Sul, incluindo os Andes, as terras baixas amazónicas, e o Brasil. Já há muito que andava a ser instigada pelos meus colegas brasileiros e brasilianistas da CUNY - Gustavo Lins Ribeiro, Lígia Simonian, Jonathan Poor, John Burdick, Robin Sheriff, mais tarde Telma Camargo - para me juntar a eles. O Antônio Carlos Souza Lima, do Museu Nacional, abriu-me as portas e apresentou-me a outros colegas ainda mais próximos dos meus interesses de pesquisa; daí conheci Sérgio Carrara, e depois 
Richard Parker, e fiz o meu próprio caminho entre as universidades, as ONG e os serviços de saúde que trabalhavam sobre a sida. Tomei contacto com um universo de pesquisa fervilhante e uma frente de actuação face à sida, tanto no plano dos cuidados de saúde como na prevenção e nas iniciativas sociais. Não tive mais dúvidas: ia fazer o meu trabalho de campo no Rio. Podia ter sido em São Paulo, mas não apenas acontece que São Paulo é diferente do padrão geral do Brasil como acontecia que eu já estava cativa do Rio. ${ }^{4}$

Enquanto desenvolvia o projecto para candidatura a agências financiadoras desloquei-me uma vez mais ao Rio, agora para acertar os termos do trabalho de campo, obter autorizações, apoios, interlocução. E foi no Rio de Janeiro, no pátio do Museu Nacional, que ouvi o Otávio Velho falar do Congresso Luso-Afro-Brasileiro, para onde iria - ele, não eu, que achei o assunto interessante mas não a ponto de pensar que no futuro iria envolver-me tanto que organizaria a terceira edição do congresso, em 1994, e viria a ser editora da revista Travessias dez anos depois. Em 1990 participei, sim, do encontro da EASA, com a emoção de assistir a algo que estava a nascer e iria certamente dar frutos. E foi durante esse encontro, algures num terraço da Universidade de Coimbra, que acabei por definir o que viria a ser uma trajectória internacional - mas feita em termos muito diferentes daqueles que eram ali enunciados. Conversava com o colega Joaquim Pais de Brito, que me instigava a voltar a Portugal, porque em Portugal é que era; e eu com a noção de que agora estava a dar um passo para mais longe, que voltaria sim, mas só depois de percorrer o caminho que estava a configurar-se mas cujos contornos, tempos, componentes, eu não conhecia de todo. Tinha passado um tempo fora, mas enquadrada num programa de doutoramento, o que em si só não acrescentava nada de radicalmente novo a um padrão em que, para aprofundar conhecimentos, se sai de uma periferia onde a ciência geralmente se consome à distância para um lugar mais central onde aquela se pratica em directo e depois se regressa para praticar de modo diluído o que se aprendeu no centro, com doses variáveis do impulso para comparar e talvez lamentar a diferença de condições entre o lá e o cá. Eu achava que estava à beira de algo diferente - talvez previsse uma mudança nessas hierarquias internacionais, nas redes a desenvolver, no horizonte sul-sul, nos emergentes? -, mas não sabia o que era. Só sabia onde devia estar: no Brasil.

\section{INTERNACIONALIZAÇÃO PESSOAL II: RIO DE JANEIRO}

Estava já no Rio de Janeiro quando ouvi os fogos e foguetes que anunciavam a entrada do ano de 1991. Não estava porém no lendário réveillon na praia de Copacabana, saudando Yemanjá juntamente com um ou dois milhões de 
pessoas vestidas de branco. Bem tinha tentado, mas em vez de Copacabana estava na Tijuca a ver e ouvir foguetes que vinham de um morro. "Morro", note-se, tanto se usava para as formações geológicas que irrompem pela cidade em ladeiras abruptas como para as favelas que nelas cresceram, nos interstícios da urbanidade, e também da lei, e também da cidadania. Hoje, transformado o Brasil num país emergente em que o futuro é construído todos os dias, o estigma das favelas reconfigurou-se e as comunidades dos morros trabalham os termos da sua cidadania; mas estávamos no início dos anos 90 e a situação era outra. O morro era a margem do asfalto; o asfalto, para lá das ruas pavimentadas, tinha casas numeradas, equipamentos e transportes públicos, direitos, cidadania; no morro tudo era mais precário, dos materiais à malha da construção e aos direitos de quem lá vivia. Do asfalto subia-se ao morro para adquirir cocaína ou outras drogas lúdicas que nos interstícios da lei ali podiam circular, e circulavam, em cadeias complexas que incluíam patrões, empregados, clientes e até soldados dos exércitos do narcotráfico. Hoje, vinte anos depois, tudo isto está documentado em filmes, livros, artigos, memórias que ajudam a decifrar as complexas relações de poder e subjugação que governavam a vida dos morros, onde além do narcotráfico havia vida, de onde vinha, aliás, grande parte da população que prestava serviços no asfalto. Mas ao tempo tudo parecia mais difuso e ao morro associava-se um continuum de fantasias e medos congregando o que se imaginava distintamente carioca - música, dança, jogo ilícito, malandragem, crime e, claro, narcotráfico. Por entre essa nebulosa irrompiam alguns sinais reconhecíveis, como o anúncio, em foguetes com sons e ritmos codificados, da chegada deste ou daquele carregamento de droga à disposição de quem a quisesse e pudesse comprar.

Nesse dia os foguetes do morro pareciam-se com os foguetes de qualquer outro lugar do Rio àquela mesma hora: assinalavam a entrada do novo ano. Talvez fossem mais exuberantes que aqueles que assinalavam a chegada de produto. Não o saberia dizer. Não conhecia todos os meandros do Rio de Janeiro e os seus códigos visuais e sonoros. Menos ainda conhecia a Tijuca. Que fazia eu à beira dos seus morros que alegremente entravam no ano de $199 \mathrm{l}$ com fogos e foguetes? Não era trabalho de campo; outros o faziam em favelas e morros. Robin Sheriff, minha amiga e colega de doutoramento na CUNY, morava no Morro dos Prazeres, no bairro de Santa Teresa - não muito longe da Tijuca, mas com todo um outro estilo e cultura -, para estudar, nos termos convencionais da observação participante, as relações raciais num Brasil que então se apresentava como se fosse imune aos males do racismo e à própria existência de racismo. O nosso querido colega Gilberto Velho, do Programa de Pós-Graduação em Antropologia Social (PPGAS) do Museu Nacional, achava "um absurdo" que uma jovem americana se expusesse voluntariamente ao que via como os riscos da favela, que incluíam a possibilidade de ser alvejada. Era assim que do asfalto se percebia a favela, exacerbados os efeitos das guerras 
do narcotráfico e dos complexos enredos de conquistas de território e controle dos morros. ${ }^{5}$

Tudo isto eu só vim a saber muito depois. A minha pesquisa era noutra área e não passava necessariamente por morros e favelas, mas antes por hospitais, ONG, laboratórios, lugares de produção e uso do conhecimento médico e social sobre a epidemia de sida. $\mathrm{O}$ que me trazia às proximidades daquele morro era absolutamente fortuito, casual, imprevisto. Aliás, nem estava no morro, via-o e ouvia-o do asfalto, mais precisamente de um confortável quarto de hospital onde recuperava de uma cirurgia de urgência. É que à chegada ao Rio de Janeiro, onde iria passar um ano em trabalho de campo, fui surpreendida por uma apendicite que não identifiquei. Bem tinha tentado chegar à cidade onde ia começar o meu "terreno" a tempo de participar do réveillon à beira-mar; mas logo na viagem de avião algo começou a correr fora do previsto, parecia um efeito da comida de bordo de uma companhia em declínio, enjoo, digestão parada por um copo de água, ou outras coisas que me iam ocorrendo enquanto os outros passageiros dormiam e eu, de pé, ia beberricando o ginger ale providenciado pela hospedeira (o único "remédio" que davam na PanAm), em completa negação da apendicite cujos sinais se apresentavam óbvios e acabariam, no dia em que cheguei, por me levar quase diretamente ao hospital de onde - depois dos devidos procedimentos de anestesia, cirurgia, excisão do apêndice, costura, recobro, etc. - assisti ao foguetório do morro da Tijuca no dia 31 de Dezembro de 1990. So much for serendipity - e a minha eterna gratidão ao bom-senso do amigo e colega Antônio Carlos, que me resgatou da minha inconsciência e me encaminhou para atendimento médico apropriado. Tendo os ouvidos cheios de histórias, factuais ou imaginárias, de antropólogos e arqueólogos imolados por triviais apendicites durante o trabalho de campo em lugares de povoamento escasso e equipamentos cirúrgicos inexistentes, não podia deixar de me sentir muito grata de este meu campo estar cheio de equipamentos hospitalares e cirurgiões experientes...

Escusado será dizer que não era essa a minha ideia de observação participante nos hospitais do Rio, e tão-pouco fiz da situação um grande momento de pesquisa. Essa seria feita em vários outros hospitais cariocas e fluminenses ao

5 Parece que tudo isto foi há muitíssimo tempo mas foram apenas duas décadas, e o Brasil era outro país, o Rio outra cidade, onde era comum ouvir dizer que não existia movimento negro por não existir racismo, ou existir de um modo muito velado e brando, insuficiente para gerar consciência negra. Livros como Racism in a Racial Democracy: The Maintenaince of White Supremacy in Brazil, de Francine Twine (1998), Dreaming Equality: Color, Race, and Racism in Urban Brazil, de Robin Sheriff (2001), e também Racial Politics in Contemporary Brazil, de Michael Hanchard (1999), e mais tarde Race in Another America: The Significance of Color in Brazil, de Edward Telles (2004), marcam um ponto de viragem; hoje o cenário é muito diferente: movimento negro, interesse pela história e antropologia das relações raciais, interpretação das favelas enquanto quilombos urbanos - e a produção académica brasileira sobre este assunto ampliou-se imensamente. 
longo dos dois anos seguintes, e em posições diferentes, fosse de pé, sentada, curvada, acocorada ou ajoelhada - mas não deitada numa cama de hospital. Se evoco esse momento na Tijuca é só para contrastar o início da década, passado no Rio de Janeiro, com o fim da mesma, que passei em Lisboa na casa onde até hoje vivo, onde me implantei firme e a partir de onde tenho feito todo um outro ciclo de pesquisas que incluem a própria cidade de Lisboa, uma antropologia do colonialismo que teve sede também em Lisboa, e me dediquei a formar gerações mais jovens de antropólogos e pesquisadores de estudos sociais da ciência. Mas isso seria na década seguinte, a de 2000. Nos anos 90 andava ainda a deambular, e muito, por lugares mais ou menos distantes. E comecei a década no Rio, e ali, em parte devido à falência da PanAm e à demora em arranjar bilhete alternativo, prolonguei a minha estadia até que me chamaram e tive de regressar a Portugal. Lembro-me que saí em vésperas do Rio 92, levaram-me ao aeroporto do Galeão pela recém-aberta Linha Vermelha, contornando os engarrafamentos da avenida Brasil; a cidade estava a transformar-se, abriam-se as vias para receber os congressistas da nova sustentabilidade mundial.

E entre esses dois dias, entre aquele em que ouvi abrir o ano de $91 \mathrm{com}$ foguetes do morro e aquele em que me despedi do Rio (em termos: voltaria muitas vezes) em meados de 92, passou-se o meu trabalho de campo. É difícil dar conta da intensidade deste trabalho, que era experimental, era urbano, era global, era sobre conhecimento científico, era sobre práticas médicas, assistência, clínica, políticas públicas, sexo, representações, identidades, trocas internacionais, fluxos de conhecimento, recomendações, ajuda internacional, relações entre agentes sociais, relações entre produtores de conhecimento, governantes, activistas, intelectuais orgânicos - e tudo ia acontecendo sob os meus olhos e sentidos, o "objecto" transformava-se enquanto o acompanhava. Uma longa história que não consegui contar de imediato, mas viria a contar sob a forma de tese que passaria a livro quase sem alterações (Bastos 1999); que contei também sob a forma de alguns artigos, uns enquanto fazia a tese (Bastos 1994a, 1994b), outros pouco depois (Bastos 1996b, 1997b, 1998b, 2003), outros muito mais tarde (Bastos 2008b, 2010a, 2010b). Como sempre, ainda no ano em que terminei o doutoramento envolvi-me num novo projecto. Se o rasgão cognitivo que me levou a formular a pesquisa sobre as relações entre a medicina tropical e o poder colonial militarizado - cujo terreno seria Goa histórica se deu na biblioteca da New York University, o caminho foi feito ao aprofundar a investigação sobre a história das doenças infecciosas, e muito se deveu ao que aprendi, ainda no Brasil, com os historiadores da medicina na Casa de Oswaldo Cruz. Aí, no Instituto de Medicina Social da Universidade do Estado do Rio de Janeiro (UERJ), no Museu Nacional da Universidade Federal do Rio de Janeiro (UFRJ), na Associação Brasileira Interdisciplinar de AIDS (ABIA), e em muitos outros lugares onde aprendi, interagi, ouvi, troquei conhecimentos, se formularam questões que se prolongariam com outro formato. 
Depois de regressar do terreno passei anos a processar a intensidade da experiência e as dificuldades decorrentes de ter formulado a equação de pesquisa de modo desastradamente visionário. Tinha ideia de que a negociação do conhecimento biomédico relevante para as doenças infecto-contagiosas - de que a sida era o caso imediato e urgente, e que tinha potencial para induzir uma mudança de paradigma - iria talvez passar por uma reconfiguração das relações de poder na produção e consumo do conhecimento científico; que o trajecto de norte para sul, ou de centros para periferias, como então se usava dizer, iria talvez dar lugar a um modo em que os habitualmente subalternizados, do sul, ou das periferias, teriam voz activa na formulação do conhecimento, das agendas de pesquisa, talvez na proposta interpretativa - tal como acontecera no campo da saúde por influência de pressões de grupos organizados, de mulheres, de gays, de minorias. Era uma hipótese teórica, desenvolvida a partir de um estudo preliminar, e, vi-o muito mais tarde, certeira: o Brasil veio mesmo a tornar-se um agente de transformação no campo da epidemia da sida e passou a ser citado, apontado, admirado, invejado e, quando possível, imitado pelo mundo fora. Só que isso aconteceu muito depois de eu ter fechado o terreno e algum tempo depois de acabada a tese. E não exactamente do modo como tinha previsto, pela formulação de modelos interpretativos para os processos infecciosos, mas sim num campo contíguo, o da política de distribuição de anti-retrovirais e assistência pública. Abordei o assunto em artigos recentes (Bastos 2008b, 2010a, 2010b). Se voltasse a fazer uma tese, seria mais modesta no alcance. Mas naquele tempo tinha uma energia que transbordava, e a tese, o terreno e o que fiz com ele assim o reflectiram.

Ao longo do período de ano e meio que durou a minha estadia no Rio consolidei laços indeléveis com colegas da antropologia brasileira, da saúde pública, da epidemiologia, da história da medicina e ciências da saúde, e do próprio campo da saúde, entre activistas, profissionais, portadores. Embora tenha iniciado entretanto todo um outro ciclo de pesquisas, esse universo de conexões e interlocução manteve-se, expandiu-se, amadureceu, fazendo com que a minha rota mais estimada, ou mesmo a mais frequente, seja no eixo luso-brasileiro. Acumulo-o com o universo norte-americano, onde cresci intelectualmente e do qual me sinto parte. E como o tempo não dá para tudo, movimento-me com menos frequência no eixo europeu.

Quando regressei de tão intenso período no Rio de Janeiro e tentei reestabelecer-me em Portugal deparei com o generalizado desconhecimento dos meus colegas relativamente ao que se passava no Brasil, equivalente ao que ocorria no Brasil relativamente a Portugal. Em parte, os congressos luso-afro-brasileiros de ciências sociais ajudariam a colmatar esse fosso, mas algo mais específico, organizado e impactante aconteceu na antropologia: uma reunião promovida pela Associação Brasileira de Antropologia quando era seu presidente João Pacheco de Oliveira Filho, amigo de longa data do programa de pós-graduação 
do Museu Nacional, e vice-presidente Mariza Peirano, da Universidade de Brasília. A reunião teve lugar no Instituto de Filosofia e Ciências Sociais (IFiCS) da UFRJ, em 1994, com o apoio entusiasmado de Yvonne Maggie. Os outros colegas portugueses (Miguel Vale de Almeida, João de Pina-Cabral, Joaquim Pais de Brito e Rosa Maria Perez) pisavam o Brasil pela primeira vez; como eu, alguns nunca mais deixaram de fazer tudo para lá voltar, e voltar, e voltar. Os colegas brasileiros presentes na reunião (João Pacheco, Mariza Peirano, Yvonne Maggie, Bela Feldman-Bianco, Gilberto Velho, Otávio Velho, Ruben Oliven, Maria Luiza Heilborn, e muitos outros) olhavam-nos com curiosidade e abertura. Poucos tinham experiência de Portugal - talvez só mesmo Bela Feldman-Bianco tivesse um conhecimento substantivo e baseado em pesquisa, quer entre os portugueses da diáspora na Nova Inglaterra, quer a partir do Centro de Estudos Sociais, em Coimbra. Mas todos estavam mais que dispostos a ultrapassar o injustificável fosso entre um país e outro, a inexistência de comunicação e de conhecimento mútuo. As condições eram diferentes de cada um dos lados: o Brasil tinha uma tradição de antropologia fortemente implantada na academia e na sociedade; tinha contado com grandes nomes internacionais nos seus primeiros anos, incluindo Lévi-Strauss, Roger Bastide, Charles Wagley. Tinha uma população indígena que atraía sem parar os interesses de antropólogos internacionais, e desenvolvera a sua própria antropologia, cujas preocupações no âmbito nacional e local não sacrificavam o padrão de qualidade internacional. Portugal estava muito distante dessa situação, mas vivia com pujança o momento de crescimento que marcou os anos 90, consolidando a condição de membro da União Europeia. Participava da EASA em pleno; lançara os congressos luso-afro-brasileiros. Em Portugal e no Brasil falava-se a mesma língua, ou quase. Era um absurdo não se conhecerem mutuamente.

\section{NOTA FINAL}

Passados quase vinte anos chegámos a um lugar muitíssimo diferente. Circulam pesquisadores, professores, estudantes. Existem bolsas-sanduíche, estágios, pós-docs, sabáticas, projectos conjuntos, acordos entre departamentos, programas partilhados, orientações coordenadas, livros a quatro mãos, a seis, oito ou mais, circulam artigos entre as revistas, faz-se comunidade sem dissolver especificidades; mantêm-se núcleos múltiplos, redes e canais que se cruzam e fazem circular conhecimento, práticas e desenvolvimentos teóricos entre vários parceiros académicos que trabalham em português - muitos dos quais trabalham também noutras línguas, mas celebram a possibilidade de privilegiar este veículo de expressão. Se na década de 1990 foram lançadas estas pontes, na de 2000 consolidaram-se de tal modo que nos anos 2010 são dadas por adquiridas, tornando-se impensável retroceder ao tempo em que cada grupo só tinha por horizonte o seu imediato, acrescido por uma miragem dos centros 
distantes com os quais se tinha uma relação hierarquizada. Cabe-nos agora, sob os constrangimentos económicos e burocráticos que a década de 2010 também trouxe, com novas relações de poder e acrescidos desafios, manter vivo o que construímos e fazer deste cenário o lugar de criatividade e aventura cognitiva a que sempre aspirámos.

\section{BIBLIOGRAFIA}

BASTOS, Cristiana, 1985, "Bruxas e bruxos no nordeste algarvio: algumas representações da doença e da cura”, Trabalhos de Antropologia e Etnologia, 25 (2-4): 285-295.

BASTOS, Cristiana, 1988, “The Northeastern Algarve and the Southern Iberia family pattern”, Journal of Family History, 13 (1): 11 1-121.

BASTOS, Cristiana, 1991a, "Etnografia, aldeia e montes: formas de povoamento no Nordeste algarvio", Trabalhos de Antropologia e Etnologia, 31 (1-4): 41-76.

BASTOS, Cristiana, 1991b, "Montes e aldeia no Nordeste algarvio", em Joaquim Pais de Brito e Brian O’Neill (orgs.), Lugares de Aqui: Actas do Seminário Terrenos Portugueses. Lisboa, Publicações Dom Quixote, 103-117.

BASTOS, Cristiana, 1993, Os Montes do Nordeste Algarvio. Lisboa, Edições Cosmos.

BASTOS, Cristiana, 1994a, "Geomorfologia do poder na produção social da ciência: a propósito da luta global contra a SIDA”, Revista Crítica de Ciências Sociais, 41: 63-84.

BASTOS, Cristiana, 1994b, "Explorações em antropologia dos processos globais: a questão da SIDA/AIDS”, Análise Social, XXIX (125-126): 483-494.

BASTOS, Cristiana, 1996a, "A escala da mudança: o tempo da serra algarvia", em Joaquim Pais de Brito et al. (orgs.), O Voo do Arado. Lisboa, Museu Nacional de Etnologia, 558$-565$.

BASTOS, Cristiana, 1996b, "Cravado na pele, o hospital: fronteiras do corpo em dias de sida”, em Miguel Vale de Almeida (org.), Corpo Presente: Treze Reflexões Antropológicas sobre o Corpo. Oeiras, Celta Editora, 184-199.

BASTOS, Cristiana, 1996c, Transnational Responses to AIDS and the Global Production of Science: A Case-Study from Rio de Janeiro. Ann Arbor, MI, UMI Dissertation Services.

BASTOS, Cristiana, 1997a, "Semeando entre as pedras: história e ecologia do minifúndio no Nordeste algarvio”, Trabalhos de Antropologia e Etnologia, 37 (1-2): 149-163.

BASTOS, Cristiana, 1997b, "A pesquisa médica, a sida, e as clivagens da ordem mundial: uma proposta de antropologia da ciência”, Análise Social, XXXII (140): 75-111.

BASTOS, Cristiana, 1998a, “(In)visible borders: ideologies of otherness and sameness in a Portuguese political frontier”, Portuguese Literary and Cultural Studies, I (1): 19-32.

BASTOS, Cristiana, 1998b, "A política de produção de conhecimento e os movimentos de resposta à sida", Etnográfica, II (1): 15-53.

BASTOS, Cristiana, 1999, Global Responses to AIDS: Science in Emergency. Bloomington, Indiana University Press. 
BASTOS, Cristiana, 2003, "A globalização da sida", em Actas dos IX Cursos Internacionais de Verão de Cascais, vol. 4 - Globalização, Novos Riscos e Ciência. Cascais, Câmara Municipal de Cascais, Instituto de Cultura e Estudos Sociais, 77-90.

BASTOS, Cristiana, 2008a, "Os estudos sociais da ciência, a antropologia e a grande fractura”, em João Arriscado Nunes e Ricardo Roque (orgs.), Objectos Impuros: Os Estudos Sociais da Ciência em Portugal. Porto, Edições Afrontamento, 107-131.

BASTOS, Cristiana, 2008b, "From global to local and back to global: the articulation of politics, knowledge and assistance in Brazilian responses to AIDS", em Maj-Lis Follér e Håkan Thörn (orgs.), The Politics of AIDS: Globalization, the State and Civil Society. Nova Iorque, Palgrave Macmillan, 225-241.

BASTOS, Cristiana, 2010a, "Tracking global flows and still moving: the ethnography of responses to AIDS”, em Marit Melhuus, Jon P. Mitchell e Helena Wulff (orgs.), Ethnographic Practice in the Present. Oxford, Berghahn Books, 135-151.

BASTOS, Cristiana, 2010b, "The social determinants of health and the hierarchies of knowledge”, em Sanjoy Bhattacharya, Sharon Messenger e Caroline Overy (orgs.), Social Determinants of Health: Assessing Policy, Theory and Practice. Deli, Orient BlackSwan, 263$-271$.

FREITAS, Marcus Vinicius de, 2012, Contradições da Modernidade. São Paulo, Editora da Unicamp.

GILBERT, Nigel, e Michael MULKAY, 1984, Opening Pandora’s Box: A Sociological Analysis of Scientists' Discourse. Cambridge e Nova Iorque, Cambridge University Press.

HANCHARD, Michael, 1999, Racial Politics in Contemporary Brazil. Durham, NC, Duke University Press.

O’NEILL, Brian Juan, e Joaquim Pais de BRITO (orgs.), 1991, Lugares de Aqui: Actas do Seminário Terrenos Portugueses. Lisboa, Publicações Dom Quixote.

SHERIFF, Robin, 2001, Dreaming Equality: Color, Race, and Racism in Urban Brazil. New Brunswick, NJ, Rutgers University Press.

TELlES, Edward, 2004, Race in Another America: The Significance of Color in Brazil. Princeton, NJ, Princeton University Press.

TWINE, Francine, 1998, Racism in a Racial Democracy: The Maintenaince of White Supremacy in Brazil. New Brunswick, NJ, Rutgers University Press. 